\title{
The New Linear Motor Drive Revolution
}

\author{
Sadao Sano* \\ (Received on October 30, 2004) \\ * Sodick Co., Ltd. \\ 3-12-1, Nakamachidai, Tsuzuki-ku, Yokohama, Kanagawa, 224-8522 JAPAN
}

\begin{abstract}
Sodick has been using the linear motor drive since 1999 successfully to bring a new revolution in the EDM machining field. Initially, the Die-sinker EDM was equipped with a z-axis liner motor drive which made high speed jumping possible and resulted in high speed machining. After this initial breakthrough, all wire-cut and die-sinker EDMs produced by Sodick were installed with linear motor drives for all axes of movement. Five years have passed since the initial production of linear motor driven EDMs and many of these earlier machines still maintain high levels of accuracy. In the future, linear motor driven machines will become more and more a necessity to ensure the creation of precision molds with high repeatability.
\end{abstract}

\section{Introduction}

During the 1990's in the machine tool industry, many limitations were discovered in the ball-screw and rotary motor systems which were widely used at the time. Users had the need for the linear motor drive system to overcome such limitations in the present drive systems. At first, only a few machine tool builders were able to apply the linear motor drive to machining centers. These applications brought much interest in industry about this new technology. The linear motor drive was not refined, however, and fundamental problems with the drive system were not overcome to allow for mass production of linear motor driven machine tools. The main problem was the thermal distortion caused by the drive system. At this time, the linear motor drive was placed at the center of the machine tool and huge amounts of thermal distortion affected the ability to maintain accuracy and precision. EDM manufacturer, Sodick, was able to find a solution for such problems and in 1999 began to manufacture Die-sinker EDMs equipped with a new generation of linear motor drive and control system that was developed completely by Sodick. The main features of these linear motor drive systems were very high speed and acceleration. Higher precision was found with these systems and that surpassed conventional drive system's ability for precise machining methods. Also through research of the linear motor drive system, the non-contact drive system and fully closed control system contributed to the long term and stable machining that is needed in industry. Soon after, Sodick began to equip all of their machine tools with the linear motor drive system on all axes.

Sodick has developed many different types of linear motor drives, including the $\mathrm{AC}$ motor, $\mathrm{AC}$ coreless motor, shaft motor, and DC coreless motor. Depending on the application, a motor is chosen that best suits the machine's needs. Water, oil, air, and natural cooling systems used in each system is chosen depending on its application. In this journal we want to show the machining faculties of our linear motor driven EDMs that has 10,000 total units shipped already.

\section{Machining Examples by Die-sinkers}

\subsection{High speed jump and high speed precision machining}

No-flushing machining by linear technology achieves high accuracy and high efficiency (see Fig.1).

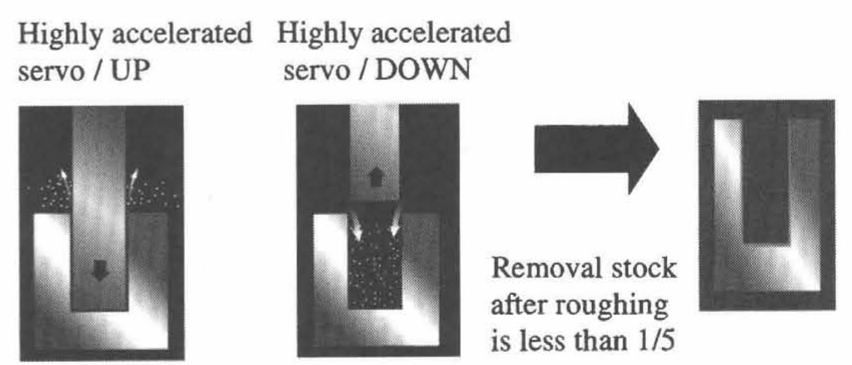

Fig. 1 Most effective chip removal by pumping

Our machine's features are as follow,

*High quality machining by high speed jump: maximum of $36 \mathrm{~m} / \mathrm{min}$.

*High acceleration servo/UP, high acceleration servo/DOWN.

*After rough machining less than $1 / 5$ of the machining allowance is left.

*Quick evacuation of chips, gas, and tar by reciprocating function of $\mathrm{z}$-axis. 
*Without secondary discharge you can get minimal workpiece expansion.

*The reduction of total machining time is possible by a decrease of electrode-workpiece burning gap.

*Shape repeatability of the workpiece is possible through stable machining conditions.

*The accurate transcription of workpiece shape and constant surface quality.

*No-flushing machining has been realized.

*Low electrode deterioration without short circuit.

\subsection{Small corner radius possible}

Our machines have SVC Circuit that gives high speed and high quality finishing. SVC's features are as follows,

*Low electrode wear

*Conventional methods allow for a radius ranging from 30-40 $\mu \mathrm{m}$. High voltage and short pulse deliver stability of machining and low electrode wear, specifically on corner radius. As a result, a surprising corner radius of $6 \mu \mathrm{m}$ can be achieved (see fig.2).

*Linear motor high speed drive system helps to make these facts possible.

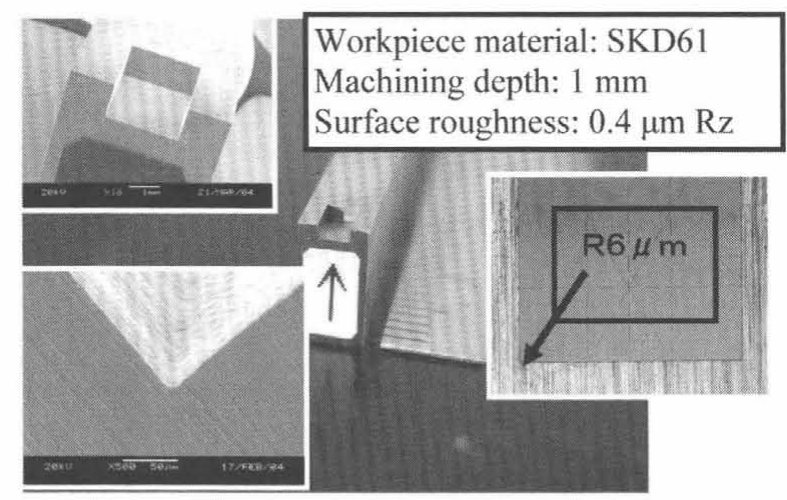

Fig.2 Shape repeatability of the workpiece

\section{Machining examples by Wire EDM}

Using small sized diameter wire, ultra fine shapes can be machined with ease. For example, using 20 $\mu \mathrm{m}$ diameter wire and minimum burning gap brought world's first $23 \mu \mathrm{m}$ groove in a sample workpiece (see Fig.3).

One example of high precision machining is show in Fig.4. The diameter and pitch are less than \pm 0.5 $\mu \mathrm{m}$. Moreover, our machines have a high-speed wire EDM power supply LQ33W that gives world's fastest machining speed, $360 \mathrm{~mm}^{2} / \mathrm{min}$ (see Fig.5).

\section{Comparison of circle eccentricity by ball-screw and linear motor}

Linear motor drive does not have any backlash as does a ball-screw system. When a circle is machined

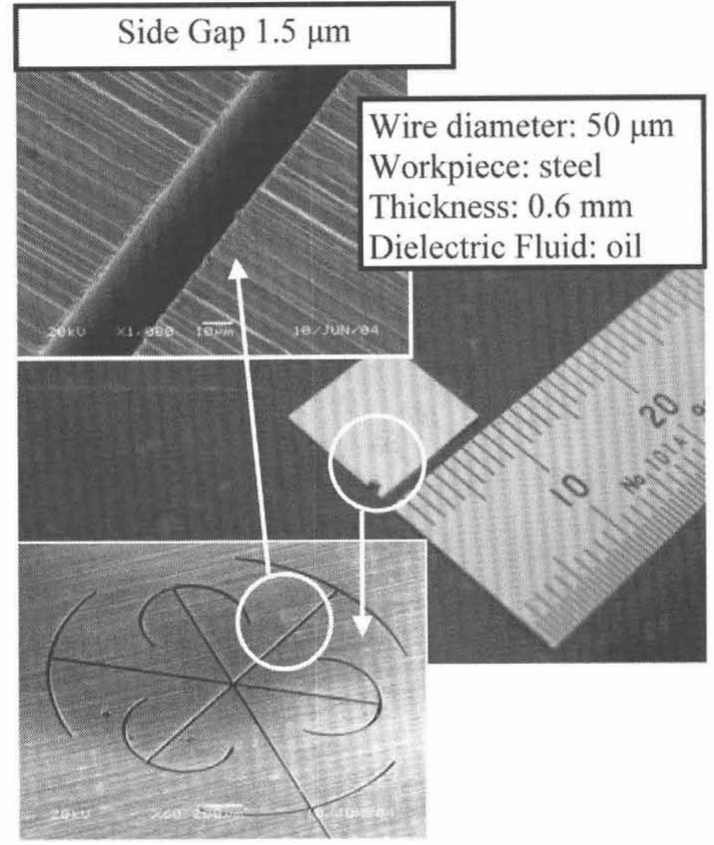

Fig. 3 The sample of minimum burning gap

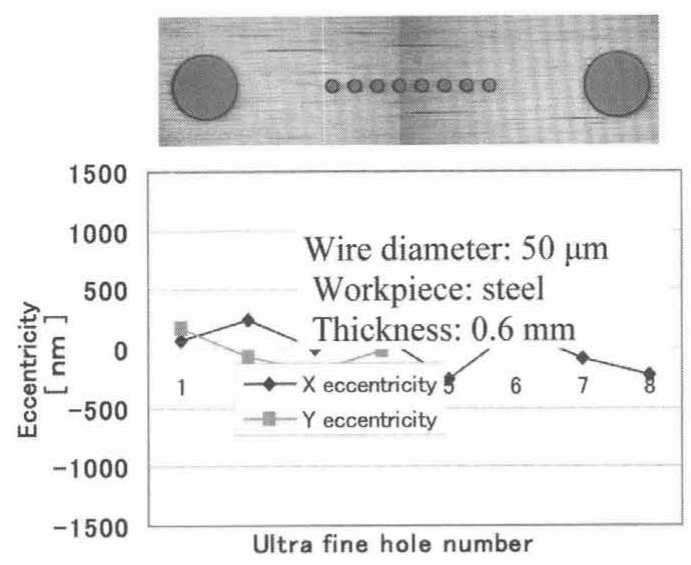

Fig.4 Sample of high precision ferrule mold

using a ball-screw many surface irregularities can be found but with a linear motor drive, such irregularities are minimal (see Fig.6 and Fig.7). Backlash can be minimized by assembly but the mechanical wear caused by using a ball-screw causes long term instability while a linear motor drive allows for long term stability and accuracy. No change in accuracy is noticed with the passing of time.

\section{Conclusion}

The trend in industry now is designing products through 3D solid models. In the next stage, mold design will be created with the use of 3D solid models as well. If the actual machine tool cannot import 3D models, we cannot use the advantage of the $3 \mathrm{D}$ models. In order to realize such advantages 
from 3D models, machine tools must be able to import these models. At the same time, stable machining and shorter machining time are necessary. Linear motor technology for machine tools meets the needs of current manufacturing industry.

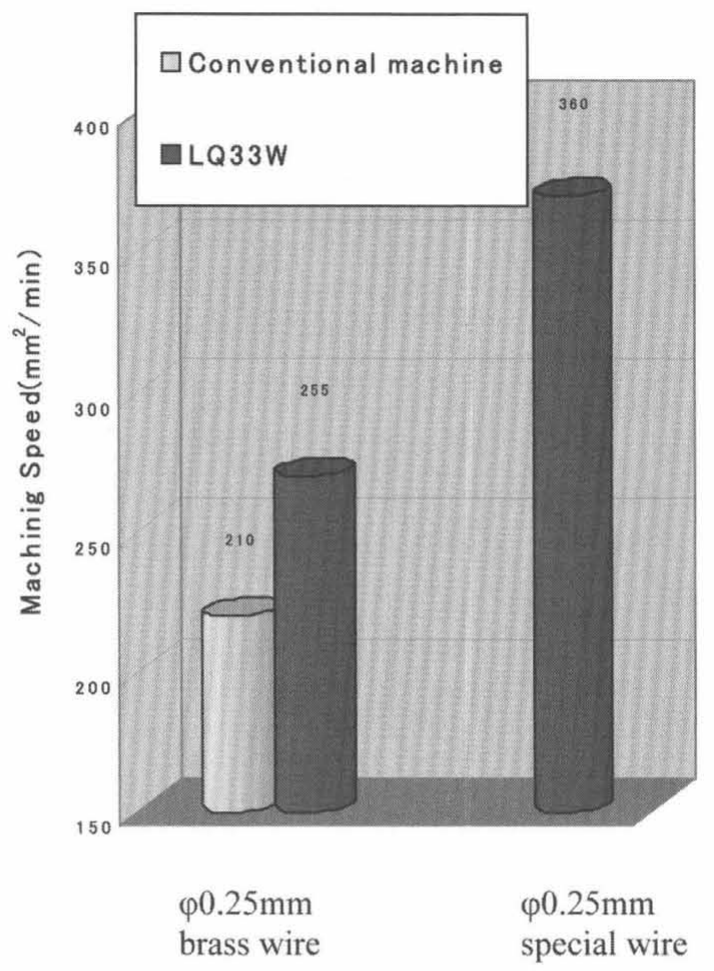

Fig. 5 Comparison for high-speed wire EDM power supply

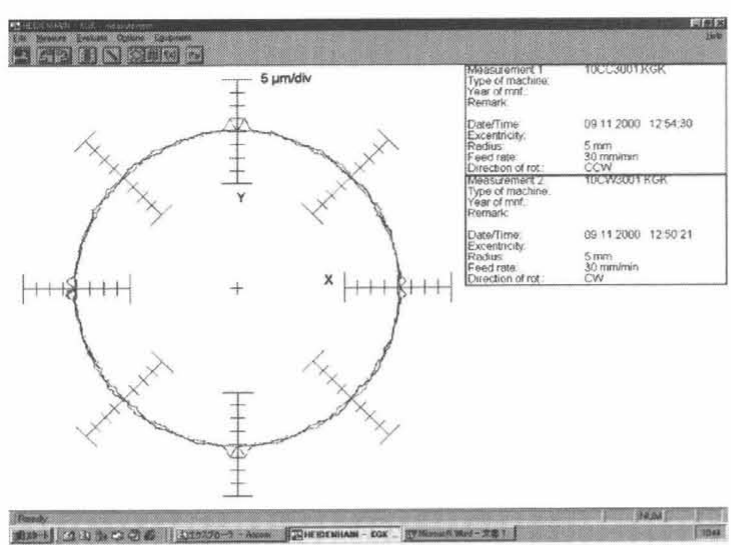

Fig.6 Eccentricity measured on conventional machine equipped with ball-screw

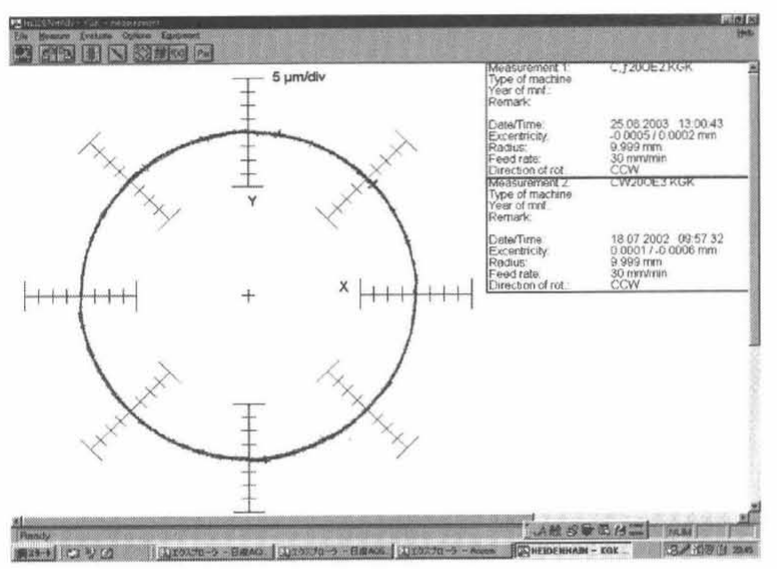

Fig.7 Eccentricity measured on linear motor driven machine 